\title{
Experimental Characterization of Extremely Broadband THz Impulse Radio Communication Systems
}

\author{
Yu, Xianbin; Vidal, Borja; Galili, Michael; Morioka, Toshio; Jepsen, Peter Uhd; Oxenløwe, Leif Katsuo
}

Published in:

Proceedings of the 40th International Conference on Infrared, Millimeter, and Terahertz Waves.

Link to article, DOI:

10.1109/IRMMW-THz.2015.7327835

Publication date:

2015

Document Version

Peer reviewed version

Link back to DTU Orbit

Citation (APA):

Yu, X., Vidal, B., Galili, M., Morioka, T., Jepsen, P. U., \& Oxenløwe, L. K. (2015). Experimental Characterization of Extremely Broadband THz Impulse Radio Communication Systems. In Proceedings of the 40th International Conference on Infrared, Millimeter, and Terahertz Waves. IEEE. https://doi.org/10.1109/IRMMW-

$\mathrm{THz} .2015 .7327835$

\section{General rights}

Copyright and moral rights for the publications made accessible in the public portal are retained by the authors and/or other copyright owners and it is a condition of accessing publications that users recognise and abide by the legal requirements associated with these rights.

- Users may download and print one copy of any publication from the public portal for the purpose of private study or research.

- You may not further distribute the material or use it for any profit-making activity or commercial gain

- You may freely distribute the URL identifying the publication in the public portal 


\title{
Experimental Characterization of Extremely Broadband THz Impulse Radio Communication Systems
}

\author{
Xianbin Yu ${ }^{1}{ }^{1 * *}$, Borja Vidal ${ }^{2}$, Michael Galili ${ }^{1}$, Toshio Morioka ${ }^{1}$, Peter U. Jepsen ${ }^{1}$, Leif Oxenløwe ${ }^{1}$ \\ ${ }^{1}$ DTU Fotonik, Department of Photonics Engineering, Technical University of Denmark, DK-2800 Kgs. \\ Lyngby, Denmark. \\ ${ }^{2}$ Nanophotonics Technology Center, Universidad Politécnica de Valencia, 46022 Valencia, Spain. \\ *E-mail: xiyu@fotonik.dtu.dk
}

\begin{abstract}
We experimentally characterize a ultrabroadband terahertz (THz) impulse radio system with up to $10 \mathrm{GHz}$ repetition rate. $\mathrm{THz}$ generation and radiation are realized in an antenna-integrated uni-traveling-carrier photodiode (UTC-PD), and $\mathrm{THz}$ reception is implemented based on photoconductive sampling by using a photoconductive antenna (PCA). We analyze the performance in terms of bandwidth and the features of the THz pulses. A $15 \mathrm{~dB}$ bandwidth of $1 \mathrm{THz}$ confirms that this $\mathrm{THz}$ impulse system has a great potential of supporting ultrafast data rates, eventually for Terabit wireless communication era.
\end{abstract}

\section{INTRODUCTION}

$\mathrm{W}$ ITH the emerging of numerous modern applications and development of signal processing and transmission, there is an increasing interest in exploring ultrahigh capacity wireless communications. Actually, wireless data rates have doubled every eighteen months over the last three decades, and are quickly approaching to $100 \mathrm{Gbit} / \mathrm{s}$ [1], particularly driven by an increasing demand for much higher speed wireless communication anywhere, anytime. To support such fast wireless data dates at and above $100 \mathrm{Gbit} / \mathrm{s}$, the radiation spectrum naturally falls into the $\mathrm{THz}(0.1-10 \mathrm{THz})$ range. So far a lot of efforts have been invested to develop high speed wireless communication systems, and most of them are operating in the millimeter-wave or sub- $\mathrm{THz}$ frequency region. For instance, $40 \mathrm{Gbit} / \mathrm{s}$ [2] and $50 \mathrm{Gbit} / \mathrm{s}$ [3] per channel wireless transmission in the W-band (75$110 \mathrm{GHz}$ ), $25 \mathrm{Gbit} / \mathrm{s}$ data transmission in $220 \mathrm{GHz}$ band [4] and $24 \mathrm{Gbit} / \mathrm{s}$ data transmission in $300 \mathrm{GHz}$ band [5] have been reported based on narrow band carrier modulation. Up to date, the fastest $100 \mathrm{Gbit} / \mathrm{s}$ data rates per wireless channel were demonstrated and realized by applying advanced modulation formats and signal processing techniques to improve the spectrum efficiency with carrier frequencies of $100 \mathrm{GHz}$ [6] and $237.5 \mathrm{GHz}$ [7], respectively. However, these narrowband frequency windows ( $<100 \mathrm{GHz}$ bandwidth) limit the highest achievable data rate according to Shannon's channel capacity theorem.

Alternatively, pulsed $\mathrm{THz}$ systems have been widely studied and used for $\mathrm{THz}$ spectroscopy. A conventional $\mathrm{THz}$ spectroscopic system employing photoconductive antennas (PCAs) for both $\mathrm{THz}$ emitter and receiver features an extremely broad bandwidth of a few $\mathrm{THz}$, while typically operating at a low pulse repetition rate of $100 \mathrm{MHz}$ [8]. Recently, such pulsed $\mathrm{THz}$ systems have attracted more research interests in developing high speed $\mathrm{THz}$ wireless communication because of its huge bandwidth [9]. So far, main efforts are however still focusing on analyzing $\mathrm{THz}$ propagation channel property [10] and shaping THz pulse [11] in a traditional $\mathrm{THz}$ spectroscopy system, due to the challenges associated with generation and detection of high repetition rate pulses.

In this paper, we characterize a $10 \mathrm{GHz}$ repetition rate pulsed $\mathrm{THz}$ wireless communication system by combining an UTC-PD as THz emitter and a PCA based THz receiver. To our knowledge, this is the first time that a $\mathrm{THz}$ impulse radio system at such a high rate is experimentally implemented.

\section{EXPERIMENTAL RESUltS}

The experimental setup of our pulsed $\mathrm{THz}$ wireless communication system is shown in Fig. 1. In the system, $10 \mathrm{GHz}$ optical pulses with $1.5 \mathrm{ps}$ pulse width are first compressed in $200 \mathrm{~m}$ highly nonlinear fiber (HNLF) and dispersion-compensated in single mode fiber (SMF), in order to generate femtosecond (fs) optical pulses. The generated femtosecond pulses are then spitted into two paths for $\mathrm{THz}$ generation at a UTC-PD and coherent detection at a PCA. In the generation arm, a polarizer is used to maximize $\mathrm{THz}$ generation efficiency since the UTC-PD is polarization dependent, and a piece of dispersion compensation fiber (DCF) is used to compensate the link dispersion before illuminating the UTC-PD. Within the $\mathrm{THz}$ propagation channel, a pair of polymer $\mathrm{THz}$ lens is used to collimate $\mathrm{THz}$ radiation from the emitter antenna and focus $\mathrm{THz}$ signals into the PCA chip.

In the detection arm, in order to fulfill peak power requirement at the PCA (typically tens of $\mathrm{mW}$ average power for $100 \mathrm{MHz} 100 \mathrm{fs}$ pulses), the generated $10 \mathrm{GHz}$ femtosecond pulses are down-sampled to $100 \mathrm{MHz}$ by gating one of them every 100 pulses. The gating process is realized by modulating a programmed pattern at an intensity modulator, and the pattern generator is externally synchronized with the laser. The down-sampled $100 \mathrm{MHz}$ optical pulses are then sent to the PCA. A delay line in the detection arm is used for scanning the $\mathrm{THz}$ pulses. The photocurrent in the PCA is first amplified by using a $40 \mathrm{kHz}$ transimpendance amplifier with gain of $10^{8} \mathrm{~V} / \mathrm{A}$, and then processed by a lock-in amplifier synchronized with an optical chopper.

The recorded $\mathrm{THz}$ train is presented in Fig.2 (a) when optical illumination power to the UTC-PD and the PCA are $10 \mathrm{dBm}$ and $13 \mathrm{dBm}$, respectively. $100 \mathrm{ps}$ time interval between two adjacent pulses confirms the success of generating and detecting $\mathrm{THz}$ signals at $10 \mathrm{GHz}$ repetition 


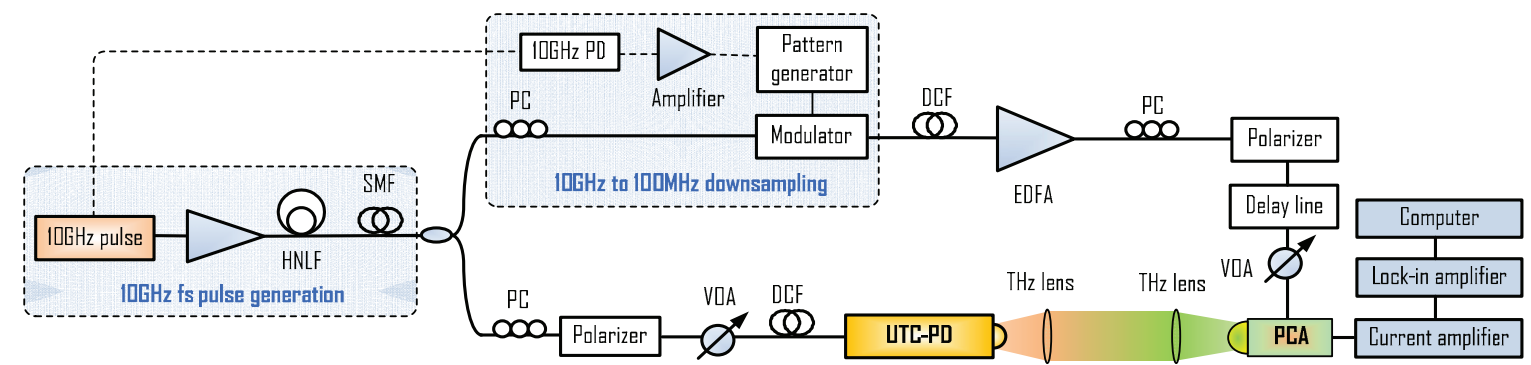

Fig.1. Experimental setup of $10 \mathrm{GHz}$ pulsed THz wireless communication system. HNLF: highly nonlinear fiber, SMF: single mode fiber, PC: polarization controller, EDFA: Erbium-doped fiber amplifier, DCF: dispersion compensation fiber, VOA: variable optical attenuator, PD, photodiode.

rate. Looking at the details of a THz pulse enlarged in Fig. 2(b), we can observe that a $\mathrm{THz}$ pulse entirely lasts around 20 ps, while the width of monocycle-like swing is only 7 ps. In principle, when the UTC-PD is illuminated by a Gaussian pulse and the bow-tie antenna within the UTC-PD radiates a $\mathrm{THz}$ pulse, the $\mathrm{THz}$ field is the first-derivative of a Gaussian profile, namely monocycle. Broadening a $\mathrm{THz}$ pulse with a long time oscillation here is because this measurement combines frequency responses of both the UTC-PD and PCA. Although the photo-response of a PCA with defects is governed by its ultrafast trapping time (can be as low as $0.1 \mathrm{ps}$ ), its long relaxation time (more than $100 \mathrm{ps)}$ also contributes to this measurement at a system level. Besides that, we can also observe some echoes in Fig.2 (b), which degrades the signal-to-noise ratio. This is caused by the reflection between the Silicon lens and GaAs chip of the PCA. By applying Fourier transformation to the time traces, the $\mathrm{THz}$ frequency spectra are shown in Fig.2(c), with a $15 \mathrm{~dB}$ bandwidth of $1 \mathrm{THz}$. Such an extremely broadband system can apparently support ultrahigh speed wireless communication. Frequency attenuation in the $0.1 \mathrm{THz}$ region in Fig.2(c) is mainly caused by the PCA cutoff frequency defined by the output aperture of PCA waveguides [12].

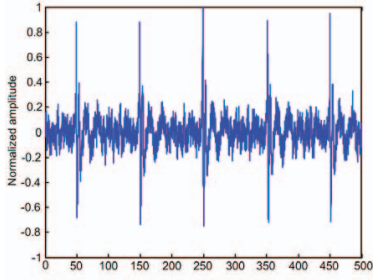

(a)

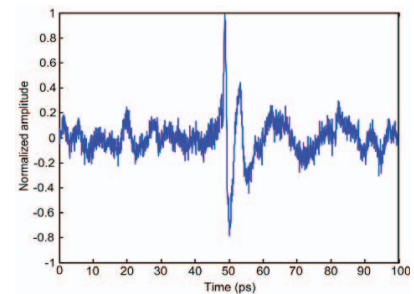

(b)

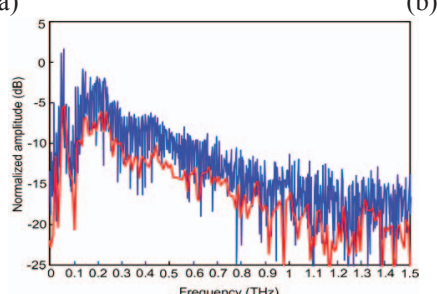

(c)

Fig. 2 (a) Received THz pulses train at a repetition rate of $10 \mathrm{GHz}$. (b) enlarged waveform of single THz pulse. (c) Fourier transformation of single $\mathrm{THz}$ pulse and $10 \mathrm{GHz} \mathrm{THz}$ pulse train.

\section{SUMMARY}

An extremely broadband $\mathrm{THz}$ impulse radio system with up to $10 \mathrm{GHz}$ pulse rate is successfully demonstrated. In the system, we use an UTC-PD for generating THz signals and a PCA for photoconductive sampling of $\mathrm{THz}$ signals. Pulse operation of $10 \mathrm{GHz}$ repetition rate is well beyond conventional $\mathrm{THz}$ pulsed spectroscopic systems. The pulsed system with an extremely broad bandwidth of $1 \mathrm{THz}$ at $15 \mathrm{~dB}$ can definitely be capable of carrying very high data rate, and hence has great potential for next generation ultrafast wireless communication.

\section{ACKNOWLEDGEMENTS}

The authors would like to specially thank NTT Electronics Corporation for lending us the UTC-PD for the experiment, and this research was supported by the ERC-PoC project TWIST within the European Union's Horizon 2020 research and innovation program.

\section{REFERENCES}

[1]. J. Federici and L. Moeller, Review of terahertz and subterahertz wireless communications, J. Appl. Phys., vol. 107, pp. 111101, June 2010.

[2]. A. Kanno, et al, $40 \mathrm{~Gb} / \mathrm{s} \mathrm{W}$-band $(75-110 \mathrm{GHz})$ 16-QAM radio-overfiber signal generation and its wireless transmission, Opt. Express, vol. 19, B56-B63, 2011.

[3]. X. Pang, et al, $100 \mathrm{Gbit} / \mathrm{s}$ hybrid optical fiber-wireless link in the Wband (75-110 GHz), Opt. Express, vol.19, pp. 22944-22949, 2011.

[4]. A. Kallfass, et al, All active MMIC-based wireless communication at 220 GHz, IEEE Trans. Microw. Theory Techn., vol. 1, no. 2, pp. 477487, Nov. 2011.

[5]. C. Jastrow, et al, $300 \mathrm{GHz}$ transmission system, Electron. Lett. vol. 44, no. 3, pp. 213-214, 2008

[6]. X. Li, J. Yu, et al, A 400G optical wireless integration delivery system, Opt. Express, vol.21, pp.18812-18819, 2013.

[7]. D. L.-Diaz, et al, Wireless sub-THz communication system with high data rate, Nature Photon., vol. 7, pp. 977-981, Dec. 2013.

[8]. P. U. Jepsen, et al, Generation and detection of terahertz pulses from biased semiconductor antennas, J. Opt. Soc. Am. B, vol.13, pp. 24242436, 1996.

[9]. X. Yu, et al, The prospects of ultrabroadband $\mathrm{THz}$ wireless communications, ICTON 2014, paper Th.A3.3.

[10]. Y. Yang, et al, Understanding THz pulse transmission in the atmosphere, IEEE Trans. THz Sci. Technol., vol.2, pp. 406-415, 2012.

[11]. J. Palací, A. Bockelt, B. Vidal, Terahertz radiation shaping based on optical spectrum modulation in the time domain, Opt. Express, vol. 20, pp. 23117-23125, 2012.

[12]. M C Schaafsma, et al, Enhanced terahertz extinction of single plasmonic antennas with conically tapered waveguides, New J. Phys., vol. 15, 015006, 2013. 